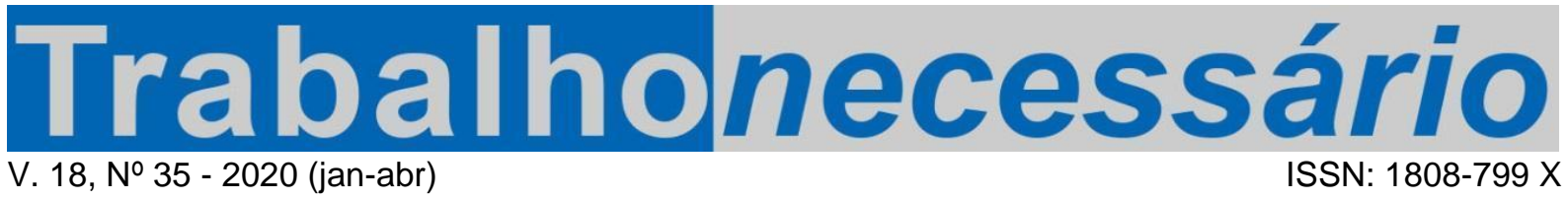

DOI: https://doi.org/10.22409/tn.v18i35.40508

\title{
EDUCAÇÃO NA CRÍTICA AO PROGRAMA DE GOTHA: UMA SÍNTESE ${ }^{1}$
}

\author{
Antonio Nascimento da Silva² \\ Deribaldo Santos ${ }^{3}$ \\ George Amaral ${ }^{4}$
}

\section{Resumo}

O artigo surgiu da necessidade de compreender a educação no contexto de crise estrutural do capital, brotando daí o interesse de discutir a proposta de educação presente na Crítica ao programa de Gotha. O relevante esforço aponta possíveis caminhos para subtrair a educação do domínio do capital. Nosso objetivo é entender a crítica de Marx à pretensão de Lassalle de construir o comunismo amparado pelo Estado e aclarar o equívoco de esperar que a burguesia eduque a classe trabalhadora.

Palavras-chave: Educação. Programa de Gotha. Classe trabalhadora.

\section{LA EDUCACIÓN EN LA CRÍTICA DEL PROGRAMA DE GOTHA}

\section{Resumen}

El artículo surgió de la intención de comprender el complejo de la educación en el contexto de crisis del capital, cuando surgió la discusión de la propuesta de educación presente en la Crítica del programa de Gotha. El esfuerzo tiene relevancia, pues busca la crítica de Marx a la pretensión de Lassalle de construir el comunismo amparado por el Estado y aclarar el equívoco de esperar que la burguesía eduque a la clase trabajadora.

Palabras clave: Educación. Programa de Gotha. Clase trabajadora.

\section{EDUCATION IN CRITIQUE OF THE GOTHA PROGRAM: A SYNTHESYS}

\section{Abstract}

This article is motivated by the need to understand education in the context of the structural crisis of capital, which prompted the interest in discussing the proposal in Critique of the Gotha Program. The present effort points likely paths to remove education from the domain of capital. Our aim is to understand Marx's critique to Lassalle's intention of building a communism supported by the Estate and to clarify the erroneous notion of waiting the bourgeoise to educate the working class.

Keywords: Education. Gotha program. Working class.

${ }^{1}$ Artigo recebido em 17/06/19. Primeira avaliação em 03/09/19. Segunda avaliação em 26/09/19.. Aprovado em 15/12/19. Publicado em 23/01/2020.

2 Mestre em Educação - PPGE/UECE; Secretaria Municipal de Educação de Capistrano - Ce; antonio.nas.silva@gmail.com; ORCID: 0000-0002-0792-990X.

${ }^{3}$ Doutor em Educação Brasileira - PPGEb/UFC; Professor da Faculdade de Educação, Ciências e Letras do Sertão Central da Universidade Estadual do Ceará (FECLESC/UECE); bolsista de Produtividade em Pesquisa do CNPq - Nível 2; deribaldo.santos@uece.br; ORCID: 0000-0001-79150885.

${ }^{4}$ Doutorando em Educação pela Faculdade de Filosofia e Ciências (FFC-UNESP/MARÍLIA), professor de História da rede pública do Estado do Ceará (SEDUC-CE), integra o Laboratório de Pesquisas sobre Políticas Sociais do Sertão Central (Lapps-UECE). Pesquisador bolsista pela FUNCAP-CE. E-mail: georgeamaralp@gmail.com ORCID https://orcid.org/0000-0002-5685-0579 


\section{Introdução}

O presente artigo analisa a questão da educação a partir do texto Crítica ao Programa de Gotha, escrito por Marx em 1875. Nesse trabalho, o pensador mouro dirige duras críticas ao programa de unificação - ocorridas no mesmo ano - do Partido Sozialdemokratische Arbeiterpartei5 (SDAP) e a Allgemeiner Deutscher ArbeiterVerein $^{6}(A D A V)$-, fundada e dirigida por Ferdinand Lassale. A união entre as duas instituições fundou o Sozialdemokratische Partei Deutschland ${ }^{7}$ (SPD). A escolha desse texto para nossa discussão não é aleatória, pois nele é possível constatar o posicionamento e a atitude política de Marx em relação à educação. Em tais reflexões, o pensador alemão, em certa medida, aponta a importância da educação no processo de transição para o comunismo.

Outros dois aspectos justificam nossa escolha pelo tema da educação. $O$ primeiro é que a educação é, desde os primórdios da sociedade, um complexo fundamental na reprodução social, sem a qual o ser social teria que reinventar a roda todos os dias. Segundo, porque nas sociedades cindidas em classes antagônicas, sobretudo no capitalismo, é atribuído à educação o preponderante papel de servir à reprodução de uma forma específica de atendimento ao que solicita o mercado capitalista: a formação de força de trabalho suscetível à produção e à realização da mais-valia.

Em estágio de crise de acumulação, o capital se lança sobre a reprodução temporariamente interrompida, o que demanda introduzir novos mecanismos de exploração que reatem o fio partido, mesmo que esta contraditória tendência seja imanente e irreversível para o capital. Novas formas de exploração exigem novas condições de reprodução social, o que atinge diretamente a classe trabalhadora.

Antes de prosseguirmos, convém reforçar que, como já se sabe, Marx não escreveu uma obra ou tratado específico sobre educação, assim como também não o fez sobre diversos outros temas relevantes. Tal fato não desqualifica, todavia, o

\footnotetext{
5 Partido Operário Social Democrata.

${ }^{6}$ Associação Geral dos Trabalhadores Alemães.

${ }^{7}$ Partido Social Democrata da Alemanha.
} 
esforço de tentarmos, com base nos diversos fragmentos sobre educação que aparecem em várias de suas obras, extrair a concepção de educação que, para Marx, estaria em concordância com um programa comunista ${ }^{8}$. É bom lembrar, com base em Tonet (2016, p. 96), que no limite, "o que importa, pois, a nosso ver, não é tanto o que Marx disse, mas o que pode ser dito a partir dos pressupostos por ele estabelecidos" sobre educação. É nesse raciocínio que podemos refletir, com base na teoria marxiana, sobre os mais variados temas, como educação, estética, política, dentre tantos outros.

Esclarecidos esses pontos iniciais, podemos situar agora a crítica de Marx (2012) cujo conteúdo efetuaremos nossa análise. O programa de unificação entre dois partidos, o POSD e o ADAV, que funda o SPD, estaria repleto de incoerências para um partido autenticamente comunista, sendo inclusive, nas palavras de Marx (2012), "desmoralizador" para tal partido. O programa de unificação teria ainda um viés revisionista, reformista, oportunista, característico de um partido liberal. Marx (2012) atribui tais características ao principal mentor do citado programa: Lassalle. Marx dirige suas críticas à influência lassalleana sobre o programa e às suas implicações na direção dos atos do partido, tomando pontos específicos do programa e mostrando em pormenores as incoerências e os desvios em relação ao comunismo. Um desses pontos é a educação.

\section{A educação gratuita ofertada pelo Estado burguês}

Antes de adentrarmos especificamente na crítica de Marx (2012) à reacionária defesa da educação assumida pelos partidários de Lassalle ${ }^{9}$, é oportuno explicitar um detalhe importante a fim de esclarecimento prévio, sobretudo aos apressados críticos de Marx e do marxismo clássico, os quais, após profundas leituras de orelhas de livros de comentadores, blogs, vídeos do youtube e postagens de facebook, fake news em whatsapp ou telegram, proclamam a ineficácia e a desqualificação absoluta da teoria

\footnotetext{
${ }^{8}$ Sobre o assunto: ver a revisão de literatura feita por José Paulo Netto (2015).

${ }^{9}$ Lassalle foi um teórico socialista do século XIX, considerado o precursor da socialdemocracia alemã. Representou uma vertente do movimento socialista do século XIX bastante fecunda no seu país de origem: a Alemanha. Na sua concepção teórico-política, o Estado exerce um papel central e as relações entre os indivíduos devem ser controladas pelo Estado.
} 
marxiana para os dias atuais. O detalhe consiste em que, para qualquer partido, aglomerado ou grupos diversos que se pretendam socialistas alinhados à teoria marxiana, é uma grande contradição querer do Estado uma educação emancipadora, ou seja, alinhada e compromissada com a instauração de uma sociedade comunista ${ }^{10}$, e que, portanto, atenda aos reais anseios e necessidades da classe trabalhadora. Isso ficará claro ao longo do texto.

A emancipação será resultante de um parto revolucionário no qual sociedade de classes, propriedade privada dos meios de produção, Estado, casamento monogâmico, dinheiro, trabalho assalariado e sua divisão social, entre outras contradições de classe, devem ser superados. O Estado burguês, antes, imprime suas concepções de educação que visam fazer de suas ideias os ideais dominantes. A forma democrática burguesa se consolidou e, estrategicamente, jogou a luta de classes para o interior do Estado. Nesse terreno, os trabalhadores são amplamente derrotados, pois o aparelhamento institucional pela classe dominante tendencialmente amortece a luta de classes, ao invés de tensionar para uma ruptura com o poder vigente que supere a dominação do capital sobre o trabalho.

A luta pela superação das condições societais burguesas, entretanto, exigirá um período de transição. Nesse período, o poder político, nas mãos da classe operária, será exercido em forma de ditadura do proletariado. Nela, o regime de opressão não será contra as pessoas, contra o ser humano em si, mas contra a dominação do capital, seu modus operandi enquanto modo de produção opressor sobre trabalhadores. Podemos entender o verdadeiro significado da ditadura do proletariado defendida por Marx quando tomamos conhecimento do desenrolar dos acontecimentos nas lutas de classes. A ditadura do proletariado é a ditadura sobre e contra o capital, sobre os proprietários dos meios de produção. Ela é o impedimento da exploração do trabalho para fins da acumulação das riquezas por uma classe, a burguesia. Ela significa a autêntica democracia desfrutada pelos verdadeiros produtores da riqueza, os trabalhadores.

${ }^{10}$ Em Marx (2012), tal sociedade é precedida pela "ditadura revolucionária do proletariado", um momento de transição ao comunismo. 
O Programa de Gotha representou a coalisão entre dois partidos operários alemães: a Allgemeiner Deutscher Arbeiter-Verein e o Sozialdemokratische Arbeiterpartei, este último fundado por socialistas dirigentes próximos a Marx. A crítica às concepções e à linha de atuação política adotadas por Lassalle, a rigor é reformista e subserviente ao Estado. De modo cristalino, as diferenças entre as concepções e as práticas revolucionárias de Marx e o reformismo social-democrata vêm desde o Manifesto do Partido Comunista.

Bem antes da crítica a Lassalle e ao programa de Gotha, Marx constata e evidencia na luta de classes, na França, que a luta pelo sufrágio universal, em 1848, e pela reforma eleitoral não representavam a luta por uma sociedade igualitária. As classes lutaram para derrubar a monarquia, porém cada classe com seu objetivo próprio. A luta operária compunha o conjunto das classes em luta, porém Marx demonstrou o desencadeamento e a consolidação da moderna sociedade burguesa: "o desenvolvimento da livre concorrência, a exploração da propriedade fundiária parcelada, a liberação da força produtiva industrial da nação, e, fora das fronteiras francesas, varreu do mapa todas as instituições feudais" (MARX, 2011, p. 26).

A luta do proletariado pela libertação da ordem burguesa e pela implantação do comunismo, por exemplo, situa a luta política contra o Estado burguês e contra a escola idealizada sob ótica liberal burguesa. A luta pela escola sob controle operário e que atenda às necessidades do trabalho, da vida social e da luta política contra as ideias conservadoras precisa estar atrelada, com efeito, à luta pela emancipação da ordem hodierna do capital.

Se, antes, a educação já era de classe, a serviço do modo de produção escravo e depois feudal, passa a estar a serviço dos interesses da burguesia capitalista, utilizada para fazer frente ao poder da Igreja e da aristocracia. O que não ocorre sem as contradições de uma sociedade cindida em classes e de um sistema educacional que se constituiu em resposta à necessidade de educar os trabalhadores para fechar o circuito de produção (SANTOS, 2012).

Por outro lado, essa contradição não implica imediatamente na negação, por parte de tais grupos comunistas, das conquistas alcançadas dentro dos limites do capitalismo. Todo leitor iniciante do marxismo clássico sabe que não constitui pauta dessa teoria negar as conquistas da humanidade, o desenvolvimento da ciência etc. 
Inclusive, esses leitores sabem também que tal desenvolvimento é, aliás, necessário para que se possa criar as condições de superação do próprio capitalismo. Definitivamente, não se trata de socializar a miséria, só os intelectuais mais ingênuos ou mal-intencionados continuam a acreditar que os marxistas, pelo menos aqueles ligados à tradição clássica, apregoam o retorno a uma condição primitiva.

Dito isso, podemos, agora, nos deter no foco da discussão principal. Isto é, entender a crítica de Marx (2012) à pretensão de Lassalle de construir o comunismo com o auxílio do Estado como uma tarefa possível. Da mesma forma, também será importante aclarar o equívoco lassalleano de esperar que a burguesia seja responsável pela educação da classe trabalhadora.

De acordo com o texto final do Programa de Gotha, o Sozialdemokratische Partei Deutschland reivindica "[...] instrução popular universal e igual sob incumbência do Estado. Escolarização universal obrigatória. Instrução gratuita em todos os estabelecimentos de ensino" (SPD apud MARX, 2012, p. 88). O cerne da crítica de Marx com relação especificamente ao tratamento dado à educação no programa de unificação é, precisamente, o fato de esta ser posta a cargo do Estado, cabendo ao poder estatal propor, fornecer e garantir a educação da classe trabalhadora.

Marx observa também, em Crítica ao Programa de Gotha, a importância de uma escola pública para os trabalhadores sem o controle do Estado e a influência da Igreja. Tais são a manifesta preocupação dos interesses de classe burguesa sobre a escola, consistindo no controle da formação das massas conforme os interesses das classes dominantes. Nessa mesma obra, Marx indica que deve haver ao menos escolas técnicas (teóricas e práticas).

Considerando, contudo, que o partido responsável por tal reivindicação se pretende como representante dos interesses da classe trabalhadora e tem no horizonte a revolução comunista, é, no mínimo, estranho que este partido simplesmente queira que o Estado garanta o direito à educação para os trabalhadores e seus filhos. Na contramão, as revoluções liberal-burguesas, em curso no século XIX e de modo mais contundente na França, são suficientes para compreender a mudança de posição de classe realizada pela burguesia: de ilustrada e revolucionária à decadente, conservadora e reacionária, investindo no Estado como instituição difusora de sua hegemonia. 
Antes de tudo, à luz do marxismo clássico, é completamente incoerente e improvável que a classe hegemônica esteja disposta a auxiliar o proletariado a sair da condição de classe subalterna despojando exatamente a burguesia. Os interesses relembramos - são antagônicos entre burgueses e proletários. Enquanto os últimos lutam para sair da situação de exploração e miséria na qual se encontram, os primeiros nada mais querem além de perpetuar seu poder e seu luxo temperado com conforto e com efemeridade. Para que a burguesia se mantenha usufruindo das benesses da cultura refinada e até mesmo de futilidades, torna-se necessário - isso é um dado ontológico - continuar explorando os trabalhadores, mantendo-os no limite, apenas vivos.

No que se refere ao processo educativo, o gerenciamento da educação pelo Estado, de modo geral, inclui-se no conjunto de ações que constituiriam o suposto apoio burguês à implementação de uma sociedade, em última instância, mais justa, jamais socialista. Apregoar que a classe trabalhadora apoie o projeto político nessas bases não desenvolve possibilidades que tensionem o sistema político do capital em favor de uma sociedade comunista.

Pretender superar o capitalismo através do próprio Estado burguês é admitir que há uma saída para a crise estrutural do capital pela via das políticas públicas burguesas, sejam elas voltadas à educação ou a qualquer outro complexo social. Mészáros (2011) tem registrado a frustrada tentativa do capitalismo de reverter sua crise por alternativas políticas. Após discutir o que chama de "grotescas fantasias", relacionando-as principalmente à velha tentativa de implantação de um socialismo de mercado e, em último termo, à humanização do capital, o filósofo húngaro afirma:

as recentes tentativas de conter os sintomas da crise que se intensificam pela nacionalização - camuflada de forma cínica - de grandezas astronômicas da bancarrota capitalista, por meio dos recursos do Estado ainda a serem inventados, só cumprem o papel de sublinhar as determinações causais antagônicas profundamente enraizadas da destrutividade do sistema capitalista. Pois o que está fundamentalmente em causa hoje não é apenas uma crise financeira maciça, mas o potencial de autodestruição da humanidade no atual momento de desenvolvimento histórico, tanto militarmente como por meio da destruição em curso da natureza (MÉSZÁROS, 2011, p. 29). 
Para esse autor, a superação da atual crise estrutural na qual estamos mergulhados é impossível, a não ser que se supere o próprio capitalismo, mas os mecanismos para essa superação jamais serão oferecidos pelo administrador da própria crise: o Estado burguês. Portanto, todas as tentativas levadas a cabo pelo capitalismo para contornar momentos difíceis logo se mostraram infrutíferas, necessitando sempre de novas medidas. Com a crescente agudização da crise, essas medidas tornar-se-ão cada vez mais ineficientes.

As medidas adotadas para salvar a economia mundial, principalmente a europeia e a estadunidense, operadas nas primeiras décadas do século XX, servemnos perfeitamente como exemplo da incapacidade de superação da crise via mecanismos internos ao Estado burguês. O próprio capitalismo que pregava o livre comércio recorre agora à manobra do controle estatal. Nesse jogo, os trabalhadores são usados para pagar dívidas de empresas privadas muitas das quais jamais voltarão do sono profundo da falência - como a Barings Securities, para usarmos o exemplo ilustrado por Mészáros (2011) ou, em terras tupiniquins, as dívidas das grandes empresas com a previdência social. No Brasil, o fardo da crise econômica e política, da decadência e do abuso social do capitalismo recaem, no fim das contas, sobre as costas dos trabalhadores, traduzido em arrocho salarial e em derrubada de direitos trabalhistas, conquistados arduamente e sob imensas contradições.

Nesse cenário de crise global e de sua irreversibilidade, é patente o fato de ser incompatível - no que se refere à educação - o caminhar do proletariado rumo ao comunismo sob as leis do capital. Veja-se, por exemplo, as mais recentes mudanças operadas pelo Estado brasileiro na educação, como a Lei 13.415/2017, a qual, mesmo rejeitada maciçamente pela população ${ }^{11}$, foi sancionada por Michel Temer, mandatário do executivo nacional após a manobra parlamentar que resultou no impeachment contra Dilma Rousseff. Essa lei é entendida pela maioria dos educadores como um retumbante atraso, possuindo como objeto de reforma, o nível básico, principalmente, o ensino médio. A lei, entre outros elementos criticados, desobriga a utilização de conteúdos essenciais para uma formação mínima nessa

\footnotetext{
${ }^{11}$ Ver: AMORIM, Gorete Maria e SANTOS, Maria Escolástica de Moura. O caráter de classe da reforma do ensino médio. Revista eletrônica arma da crítica. № 7/dezembro, 2016.
} 
etapa da educação básica, autorizando a contratação de professores que possuem apenas o notório saber, sendo duvidosas as formas de comprovação da notoriedade desse saber. Ou seja, ações que concretizam ao extremo a ideia de instrução a contagotas, nada mais além daquilo imediatamente necessário para o mercado do emprego/desemprego que toca o aparato capitalista.

Desde o momento em que a Revolução Burguesa entendeu o grande salto dado pela indústria moderna, passou a defender cada vez mais - por via estatal - a instrução do operário para que ele dominasse, mesmo que minimamente, os instrumentos necessários para a execução de sua função. Portanto, é bem verdade que, em termos de educação, historicamente foi concedido ao trabalhador apenas essa pequena "misericórdia" necessária à execução de uma função específica para atender às vicissitudes do mercado capitalista.

A burguesia carrega na educação não uma possibilidade de realmente esclarecer as massas, como uma via para elevar a consciência do povo, de torná-lo crítico. Mas como uma oportunidade de otimizar a indústria, torná-la mais lucrativa ou mesmo adestrar a formação da consciência sobre um viés ídeo-político condizente com as condições do capital em crise. Isto é, a educação é para o capitalismo apenas uma fonte de lucro, direta ou indiretamente.

Não é por acaso que órgãos internacionais passaram a investir nos sistemas educacionais de países do capitalismo periférico, procurando torná-los cada vez mais mercadológicos (SANTOS, 2012). Tal situação, todavia, tem seus reais objetivos mascarados pelo discurso de ajuda ao desenvolvimento dos países pobres. A educação tem sido vista pelos organismos internacionais, desde o século $\mathrm{XX}$, como a solução para os problemas sociais oriundos das desigualdades econômicas para tais países. A real intenção dos países imperialistas é construir novos mercados, novas fontes de consumo e de mão de obra dócil, barata e medianamente qualificada. Para as agências multilaterais, não há interesse em educar os trabalhadores para que eles compreendam melhor a humanidade que mora em cada pessoa. Para a atual conjuntura de imensos avanços tecnológico, contraditoriamente, basta que os trabalhadores saibam ler, escrever, contar e apertar parafusos teleinformatizados e mecatrônicos. A prova de como o capitalismo imperialista enxerga a educação como um meio para expandir seus lucros reside no aumento significativo do montante de 
investimento que é destinado ao ensino profissionalizante, seja ele básico ou superior, em detrimento de investimentos na universidade gratuita, pública, laica e de qualidade.

As investigações de Santos (2012) constataram que o aligeiramento, a fragmentação e o esvaziamento do conhecimento chegam com toda força ao ensino superior dos países da periferia do capital, notadamente no Brasil. Alarga-se a universidade pela precarização do ensino não-universitário. Um ensino superior distinto dos bacharelados clássicos que, por seu caráter de classe, são reservados, geralmente, à elite e aos extratos intermediários da sociedade. Esse engenhoso processo educativo de nível superior destinado, especificamente, aos filhos de trabalhadores por intermédio dos cursos sequenciais e das chamadas graduações tecnológicas é, muitas vezes, desenvolvido através da propalada educação à distância, tornando precário mais ainda o processo educativo.

A educação, na ordem vigente, assume responsabilidades e finalidades contrapostas ao seu real e histórico papel social. De um lado, sob apelo das agências multinacionais, ela é chamada a resolver os problemas da pobreza dos países periféricos e, de outro, amparada no discurso sobre o capital humano, a própria pessoa se mercadoriza (coisifica), tornando-se meio para a reprodução do capital. No fulcro da crise do capitalismo contemporâneo, o complexo educacional assume uma importante missão para a obtenção de lucro pelas empresas capitalistas e se torna uma forma de potencializar novos mercados, de inserir inovadores espíritos na lógica do empreendedorismo consumista.

\section{As ingênuas exigências de Lassalle e seus rebatimentos contemporâneos}

Lassalle não viveu a crise profunda que o mundo experimenta hoje, mas sua lógica reformista é a mesma, mudar o que tem que ser mudado dos atuais agentes políticos da chamada esquerda democrática e seus assemelhados espalhados pelo mundo ou, mesmo, qualquer outro reformista, pois pretende que o Estado burguês banque gratuitamente a educação popular dos trabalhadores. Se por popular, ele entende extensível a todos, o capitalismo procura providenciar, quase que completamente, a universalização da educação básica, pois é de seu interesse ter 
trabalhadores "hábeis e competentes". Quanto à gratuidade, existe a contradição entre o público e o privado. No Brasil, destacadamente após a LDB № 9.394/96, os empresários da educação questionam o monopólio da educação gratuita estatal, defendendo, por seu turno, que o Estado pague à iniciativa privada para que esta oferte ensino gratuitamente para o estudante (aquele que melhor se adaptar às exigências mercadológicas).

Não é preciso reforçar que a iniciativa privada é mais interessante para o capital - desde que tenha apoio estatal. Isto é, o Estado, encontrando-se na histórica condição de administrador dos interesses burgueses, procura, cada vez mais e hoje mais que nunca, ampliar o volume de dinheiro público investido em empresas privadas, o Programa Universidade para Todos (ProUni) e o Fundo de Financiamento Estudantil (Fies) servem de exemplos desse tipo de artimanha utilizando o complexo educacional ${ }^{12}$. Destarte, como esse caminho não alcança ainda toda a demanda e nem todos podem pagar, subsiste ainda a educação escolar pública administrada pelo Estado burguês (dificilmente laica, menos ainda de qualidade).

Com efeito, as ingênuas exigências de Lassalle, mesmo em seu tempo, já haviam, em certa medida, sido postas em prática pelo Estado burguês, inclusive com algum nível mínimo de qualidade. Mas o que é qualidade na educação para o Estado burguês? Eis os elementos postos por Costa (2010, p. 166-7) que, segundo entendemos, aproximam-se de uma resposta a esta indagação:

1) esvaziamento do professor como transmissor de objetivações culturais elaboradas no desenvolvimento histórico da humanidade; 2) enaltecimento do pragmático sobre o teórico; [...] 4) desprezo do aspecto intelectual do processo de aprendizagem em função de uma elevação unilateral do lúdico; [...] 7) extrema valorização do fazer ao lado de certa indiferença pelo saber; [...] 9) exacerbação do particular e quase anulação do universal [...].

De forma resumida, aqui está, entre outras inúmeras precarizações, o progresso no qual está envolvida a educação burguesa. Tais aspectos são, dia após dia, mais acentuados, indicando já as intenções do capitalismo para com a educação escolar. Esse é o programa de qualidade oferecido aos trabalhadores no âmbito

12 Ver http://siteprouni.mec.gov.br/ e, http://sisfiesportal.mec.gov.br/. 
educacional. É por ele que clama a reivindicação de Lassalle e dos reformistas da ordem do dia.

Mas será essa a educação da qual realmente necessita a classe trabalhadora? Não nos deteremos por demasiado nessa questão, pois a mesma, embora continue em aberto, há muito vem sendo discutida por outros autores ${ }^{13}$. Apenas queremos sublinhar que, de modo geral, a educação entregue ao trabalhador no capitalismo é uma espécie de "misericórdia compensatória". Nossa denúncia direciona-se para os seus defensores, que, como Lassalle, recebem-na como se fosse o máximo a que os trabalhadores podem ter acesso.

Em decorrência da própria situação de miséria das massas, essa "misericórdia compensatória" dada aos trabalhadores pelo capitalismo é aceita como uma dádiva. As famílias que, quando muito, fazem duas precárias refeições diárias, matriculam seus filhos em uma escola onde a criança ou jovem pode ao menos comer, é difícil não considerar essa educação "o máximo".

Com base nos clássicos do marxismo, é claro que há muito mais para ser oferecido do que reza a proposta burguesa de educação escolar, de modo que não podemos, mediante a irresponsabilidade de absorvermos um modesto saber, limitarmo-nos a aceitar essa esmola em forma de "misericórdia compensatória". Da mesma forma, precisamos tornar isso claro para as massas. Não queremos apenas apertar o parafuso, mas também conhecer a mecânica, a química e seu estado imanente, o processo pelo qual é extraído a matéria-prima e em que circunstâncias isso se deu. Queremos apreender as relações que o fizeram agora estar na fábrica e que o levarão até o automóvel particular de alguém. Queremos prática e teoria juntas ao deleite da fantasia espiritual; fazer, pensar, criar, sonhar. Queremos para todos os trabalhadores e seus filhos o comando de nosso trabalho e do produto dele. Não precisamos da educação burguesa, não queremos uma "misericórdia compensatória", seja ela dada pelo poder divino ou pelo estado burguês.

Nosso objetivo não é outro senão compreender as críticas de Marx dirigidas às propostas de unificação do Sozialdemokratische Arbeiterpartei (SDAP) com a Allgemeiner Deutscher Arbeiter-Verein, especialmente no que diz respeito à

13 Tonet (2016), Mészáros (2008), o próprio Marx (2012). 
educação. A importância teórica desse entendimento consiste, precisamente, no fato de que as críticas se dirigem a elementos da proposta lassalliana que ferem os legítimos princípios de um programa autenticamente comunista e, portanto, de uma concepção de educação que atenda a tal programa.

Dessa forma, compreendê-los significa conhecer melhor o próprio comunismo proposto e defendido por Marx, bem como pelos clássicos do marxismo. Esse entendimento nos possibilita apontar, de forma clara e contundente, os equívocos recorrentes nas atuais e messiânicas propostas de reformas para a salvação do sistema capitalista, muitas vezes, às custas da educação. Destarte, diante do que expomos, não poderíamos chegar a outra conclusão se não a que inexiste possibilidades de se atingir uma sociedade humana emancipada através do capitalismo com o apoio da burguesia e uma educação bancada e planejada por essa burguesia e seus legatários políticos. Não obstante, é da própria contradição inerente ao capitalismo que brotam as possibilidades e as ferramentas para superá-lo e isso, de modo algum, implica em humanizá-lo.

As propostas de Lassalle tentam justamente mascarar essa real impossibilidade, fazendo crer que, de fato, há uma saída pela via do próprio Estado burguês. Tal mascaramento procede, segundo nossa análise baseada em Marx (2012), por duas vias entrelaçadas. Primeiro, distorcem-se os fundamentos teóricos do comunismo e, então, traçam-se ações que conduzem o movimento comunista dos trabalhadores a uma postura de não enfrentamento, de consenso aos ditames burgueses. Grosso modo, é algo assim que acontece hoje com a chamada esquerda progressista no Brasil.

Como vimos, aceitar uma educação meramente profissionalizante, com laicidade e qualidade duvidosa, que hipoteca o futuro do jovem, para usar a expressão gramsciana, é conformismo, é calar-se diante dos projetos reprodutivistas do capitalismo e compactuar com o processo cada vez mais agudo de exploração do ser social pelo capital. Como argumentamos, tal educação pretende apenas qualificar as massas para servir docilmente ao capital em crise, negando aos trabalhadores o conhecimento da realidade e conferindo falsa legitimidade ao argumento de que teoria e prática são polos opostos. 
Essa postura de buscar recursos para superar o modelo capitalista de produção por dentro do próprio Estado Burguês - que não se limita à educação - é reflexo, em Lassalle e em contemporâneos, da proposital distorção do programa socialista para a obter vantagens particulares ou, como diz Marx (2012), um oportunismo lassalliano muito em moda nos dias atuais.

As afirmações sobre educação presentes no programa de unificação de Gotha representam uma espécie de abertura de modo a facilitar a cooptação do partido revolucionário pela burguesia mediante implementação das ideias desta última pela via da educação. Tal característica é ressaltada por Marx (2012) ao chamar de "oco" os argumentos de Lassalle, pois esses estariam a permitir as mais variadas conclusões, sem uma postura firme em defesa do proletariado.

Do ponto de vista teórico, Lassalle já falha nos fundamentos, naquilo que é basilar para o comunismo, qual seja, o trabalho. Ele não considera ser o trabalho uma síntese humano-natureza, pois afirma serem a riqueza e a cultura provenientes apenas do trabalho. Mas, não esclarece o tipo de trabalho. Disso podemos concluir que a abelha produz riqueza e cultura ao construir sua colmeia, por exemplo. Não levar em conta de forma rigorosa os elementos que se constituem como base do marxismo, leva, como exemplificamos, a afirmações que chegam a ser contrapostas ao autêntico programa socialista.

As interpretações falseadas de base teórica, que são expressão do proletariado, produzem ações práticas igualmente incompatíveis e contrapostas à real necessidade da classe trabalhadora. Procuramos ressaltar, em largas linhas, que a educação burguesa visa a reprodução do capital, mesmo que tal categoria disponha de autonomia relativa em relação à organização da produção material da riqueza. É por essa relativa autonomia que não faz sentido abandonarmos a luta em prol de uma educação que não seja, de fato, aquela que possibilite aos trabalhadores vislumbrar outra perspectiva de sociedade, outro horizonte: a emancipação humana.

Essa problemática urge que busquemos sistematicamente entender a estrutura da sociedade, baseados na teoria que mais se aproxima da realidade, porém, sem enrijecê-la. A crise estrutural da sociabilidade burguesa obriga-nos a traçar planos e estratégias práticas que enxerguem outro horizonte além do desastre que tem sido o capitalismo. É preciso se organizar e articular uma resistência. Do contrário, duas 
opções nos restam: a barbárie ou a "misericórdia divina, mesmo que por via do estado". Esta luta não se resume à educação, mas passa inevitavelmente por ela, e como afirma Marx (2012, p. 46), "é o Estado que, ao contrário, necessita receber do povo uma educação muito rigorosa".

\section{Notas conclusivas}

A educação burguesa, com sua "qualidade, gratuidade, laicidade" e abrangência não pode suprir os anseios da classe explorada. O que afirmamos energicamente com relação à educação, serve, de modo geral e respeitando as especificidades, em última instância, para toda superestrutura ideológica. Todos os complexos da superestrutura capitalista, embora por mediações dialeticamente distintas, prestam-se, principalmente, ao processo de reprodução do capital e não para a sua superação. Em poucas palavras: não há saída para o capitalismo por dentro do Estado burguês, como pretendem Lassalle e os reformistas de ocasião.

Como indicamos na introdução, procuramos nesse breve texto, discutir a crítica de Marx (2012) dirigida à proposta de unificação dos partidos SDAP e ADAV que culminou no SPD. Detemo-nos, especialmente, na educação, evidenciando, as distorções Lassalleanas e a incoerência de suas propostas com a demanda por uma sociedade emancipada, portanto, uma sociedade comunista ou que aponte para esta. Nossa discussão pautou-se no texto de Marx intitulado Crítica ao programa de Gotha. Embora existam vários outros textos até clássicos do marxismo, reafirmamos que a nossa escolha tem por motivação núcleos teóricos que remetem à consistência metodológica, à união teórico-prática e ao papel do complexo da educação no plano de transição.

Podemos afirmar, na esteira de Marx (2012), que Lassalle está equivocado e mal-intencionado ao pretender, enquanto proposta revolucionária de um partido comunista, obter do Estado as condições e o apoio para estruturar uma educação alinhada aos propósitos comunistas. O Estado, como gerenciador dos interesses da classe dominante, apenas concederá formação para os trabalhadores na medida em que tal formação garanta a perpetuação da ordem constituída e que, de modo algum, possibilite aos trabalhadores ascender à emancipação humana. 
Como dissemos inicialmente, não se pretende, de modo algum, fechar o debate sobre os temas abordados nessa argumentação. Pelo contrário, procurou-se apenas ampliá-los e contribuir com a tematização aprofundando-a. Dessa forma, justifica-se o subtítulo acima que não se refere senão a parciais conclusões. Ademais, essas já estão implícitas, no decorrer de nossa exposição, carecendo, no máximo, de uma reafirmação mais sintética e clara, haja vista que o merecido suporte teóricoexplicativo foi dado nas possibilidades desta comunicação.

\section{Referências bibliográficas}

AMORIM, Gorete Maria; SANTOS, Maria Escolástica de Moura. O caráter de classe da reforma do ensino médio. Arma da crítica. № 7/dezembro, 2016.

BRASIL. Lei n $^{\circ} 9.394$ de 20 de dezembro de 1996. Presidência da República, Casa Civil, Subchefia para assuntos jurídicos; 1996. Disponível em: <http://www.planalto.gov.br/ccivil_03/leis//9394.htm>. Acessado em: 24 Jan. 2018.

BRASIL. Lei no 13.415 de 16 de fevereiro de 2017. Presidência da República, Casa Civil, Subchefia para assuntos jurídicos; 2017. Disponível em: <http://www.planalto.gov.br/ccivil_03/_ato2015-2018/2017/lei//13415.htm>. Acessado em: 24 Jan. 2018.

COSTA, Frederico Jorge Ferreira. Marxismo, história e educação. In: Vozes da FACEDI: Reflexões, experiências e perspectivas em educação. Fortaleza - CE: EDUECE, 2010.

MARX, Karl. Crítica ao programa de Gotha. São Paulo: Boitempo, 2012.

. 018 de Brumário de Luís Bonaparte. São Paulo: Boitempo, 2011

MÉSZÁROS, István. A crise estrutural do capital. $2^{\text {a }}$ edição. São Paulo: Boitempo, 2011.

. Educação para além do capital. $2^{\underline{a}}$ ed. São Paulo: Boitempo, 2008.

SANTOS, Deribaldo. Graduação tecnológica no Brasil: crítica à expansão do ensino superior não universitário. Curitiba: CRV, 2012.

TONET, Ivo. Educação contra o capital. Coletivo Veredas, 2016. 